\title{
Adolescents' Conflict Management Styles with Mothers: Longitudinal Associations with Parenting and Reactance
}

\author{
Lies Christine Missotten ${ }^{1} \cdot$ Koen Luyckx $^{1} \cdot$ Susan Branje $^{2} \cdot$ Stijn Van Petegem $^{3}$
}

Received: 28 September 2016 / Accepted: 5 January 2017 / Published online: 18 January 2017

(C) Springer Science+Business Media New York 2017

\begin{abstract}
Adolescents' conflict management styles with parents are assumed to have an important impact on the quality of the parent-adolescent relationship and on adolescents' psychosocial development. Longitudinal research investigating possible determinants of these conflict management skills is scarce. The parenting context and adolescents' tendency to reject maternal authority are expected to shape adolescents' conflict management styles. Therefore, the present three-wave longitudinal study focuses on how parenting and adolescents' reactance relates to adolescents' conflict management styles and conflict frequency with mothers over time, and whether reactance may also explain the associations between parenting and certain conflict variables. We addressed these research questions by using a hybrid cross-lagged panel model with parenting as a latent variable (i.e., supportive parenting) and the other variables as manifest variables. Supportive parenting was measured by four well-known parenting dimensions: autonomy support, responsiveness, psychological control, and harsh control. Four conflict styles were investigated: positive problem solving, withdrawal, conflict engagement, and compliance. Questionnaires were completed by 812 adolescents at three annual waves (52\% girls at Time 1). Supportive parenting was associated with fewer conflicts,
\end{abstract}

$\triangle$ Lies Christine Missotten

lies.missotten@kuleuven.be

1 KU Leuven, School Psychology and Development in Context, Tiensestraat 102 - box 37, 3000 Leuven, Belgium

2 Utrecht University, Youth and Family, Heidelberglaan 1, 3584 CS, Utrecht, The Netherlands

3 Université de Lausanne, Center de recherché sur la famille et le développement, Quartier UNIL-Mouline, Géopolis, CH-1015, Lausanne, Switzerland more positive problem solving, and less compliance and reactance over time. Reactance was associated with more conflicts, conflict engagement and withdrawal, and less compliance. We did not find evidence for the mediating role of reactance in the over-time associations between parenting and adolescents' conflict management and frequency. Both parenting and reactance appeared important and unique determinants for adolescents' conflict management styles and frequency.

Keywords Adolescent conflict management behavior Parenting $\cdot$ Reactance $\cdot$ Longitudinal

\section{Introduction}

Both popular and scientific sources consider conflicts as an essential and normative feature of parent-adolescent relationships due to the realignment of the parent-adolescent relationship from being vertical to more horizontal (Collins and Steinberg 2006). The expectancy-violation realignment model also suggests that parent-adolescent conflicts are important catalysts for autonomy development and relational functioning (Collins et al. 1997). However, there is also considerable evidence that frequent and hostile conflicts have a negative impact on adolescents' functioning (Weymouth et al. 2016). Several scholars therefore have argued that the way conflicts are handled might be more important than the presence of conflicts (Adams and Laursen 2007). Studies have demonstrated that conflict management styles indeed have an important impact on the quality of the parent-adolescent relationship and on adolescents' personal development (Caughlin and Malis 2004a; 
2004b). However, it still remains unclear why certain adolescents handle conflicts in a constructive manner while others have more difficulties in handling conflicts adequately. Indeed, studies investigating determinants of adolescents' conflict management styles and conflict frequency are rather scarce (Eisenberg et al. 2008), especially from a longitudinal perspective.

The quality of the parent-adolescent relationship is one potential important factor. The family context is supposed to play a crucial role for adolescents' psychosocial development in general, as well as for the development of a number of more specific skills, including their skills for handling conflicts constructively (Collins and Steinberg 2006; Grotevant and Cooper 1985; Laursen and Collins 2009). A positive and supportive parent-adolescent relationship is assumed to foster adolescents' autonomy development (Soenens et al. 2007; Van der Giessen et al. 2014; Van der Giessen et al. 2015) and would give adolescents the opportunity to express their own point of view during conflicts. In such an open climate, conflicts are dealt with in a more constructive manner. Negative and controlling parent-child interactions, by contrast, undermine adolescents' autonomy, and therefore might evoke reactant and oppositional behaviors (Van Petegem et al. 2015). Hence, such a climate might hinder the development of constructive conflict management strategies and may contribute to even more conflicts. Drawing upon this reasoning, we examined maternal parenting as one potential determinant of adolescents' conflict management styles and conflict frequency. In addition, we tested whether adolescents' reactance toward maternal authority would relate to adolescents' conflict management styles, and whether reactance would be a possible intervening mechanism between parenting and adolescent conflict management styles and frequency.

\section{Conflict Management}

Conflict management styles can be defined as the behaviors people enact during conflicts. According to the dual concern model (Pruitt and Carnevale 1993), conflict management styles can be situated along two dimensions, namely concern for the self and concern for others. Based on this theoretical framework and the empirical literature on marital and parent-adolescent conflict management (Kurdek 1994; Rubenstein and Feldman 1993; Van Doorn et al. 2008), we focused on four conflict management styles that adolescents and parents may use when they have disputes with each other. Positive problem solving involves trying to understand the other's point of view and negotiating the conflict effectively to find a compromise, and thus reflects a high concern for the self and for others. Conflict engagement also reflects a high concern for the self but a low concern for the other, and involves destructive behaviors such as attacking the other verbally, being defensive, or losing self-control. Withdrawal involves avoiding the problem, avoiding talking, and becoming distant, and thus reflects low concern for both the self and the other. Finally, compliance involves giving in to the other party without expressing one's point of view, which reflects low concern for the self and high concern for the other. Several studies have demonstrated that more negative conflict management styles, such as withdrawal and conflict engagement, were related to more maladaptive adolescent outcomes, such as depressive complaints, externalizing behaviors, lower self-esteem and relationship quality (Branje et al. 2009; Caughlin and Malis 2004a, b). Longitudinal work has shown that the changes in adolescent conflict management reflect the maturation process in the parent-adolescent relationship. Adolescents' use of positive problem solving with mothers increased over time, whereas their use of conflict engagement and withdrawal decreased (Van Doorn et al. 2011). In the present study, we aimed to understand why adolescents may differ in their use of these conflict tactics by examining potential determinants of adolescents' conflict management styles and frequency. As argued by Collins and colleagues (e.g., Collins and Steinberg 2006; Laursen and Collins 2009), the general parenting context may be one important factor that explains why some adolescents develop more adaptive conflict management styles.

\section{Parenting Dimensions}

Although peers become gradually more important, the family remains a vital context in which adolescents construct an arsenal of social skills (Bronfenbrenner and Morris 2006; Laible et al. 2000). Interactions with parents within a certain emotional climate provide adolescents with a platform to learn how to deal with conflicts (Parke and Buriel 2006). Numerous studies indeed have underscored and demonstrated the importance of parenting for adolescents' development in general (e.g., Steinberg and Silk 2002). For instance, high maternal support and low rigid control have been positively related to adolescents' social competence in the peer context (Laible and Carlo 2004). However, relatively few attempts have been made to relate parenting to adolescent conflict management skills toward parents (either cross-sectionally or longitudinally; Eisenberg et al. 2008). Drawing from the vast literature on the effects of parenting on adolescents' socio-emotional development, parenting is assumed to play an important role in adolescents' conflict management styles (Eisenberg et al. 2008; Laible and Carlo 2004). For the present study, because conflicts are emotional events (Jones 2001), we focused on those parenting dimensions that shape the emotional climate of parent-adolescent relationships (Darling and Steinberg 1993). Based on Janssens' et al. (2015) work on the factorial 
structure of parenting, two support and two control dimensions are included. Responsiveness and autonomy support are two parenting dimensions that are indicative of a supportive parenting climate. Responsiveness is the parents' capacity to attune to children's needs and to react in a warm and involved manner in times of distress. Autonomy support refers to parents' sensitivity to and support for adolescents' personal values and interests (Grolnick 2002). The two control dimensions, psychological control and harsh control, are intrusive and maladaptive ways of parenting. Psychological control can be described as the use of manipulative techniques that intrude in the child's psychological world, such as guilt-induction, conditional loving, or shaming (Barber 1996). Harsh control refers to more openly coercive techniques, such as yelling or hitting (Nelson and Crick 2002).

These four parenting dimensions have been linked to adolescents' psychosocial functioning and health behaviors, with psychological and harsh control typically being positively associated with indicators of maladjustment (including internalizing and externalizing symptoms) and negatively with indicators of adaptive functioning; and responsiveness and autonomy support being positively linked with more adaptive functioning (including higher well-being, social competence, and less health risk behaviors; e.g., Barber 1996; Borawski et al. 2003; Steinberg 2001). The literature on the impact of parenting on adolescents' functioning mainly differentiates between supportive and controlling parenting, In addition, several studies reported moderate to high correlations between parenting dimensions (Janssens et al. 2015; Kuppens et al. 2009), potentially resulting in problems with multicollinearity (e.g., Brody et al. 2001). To remedy this problem in the present study, parenting was conceptualized as one latent construct with responsiveness and autonomy support as positive indicators and psychological and harsh control as negative indicators. Previous studies have also combined several parenting dimensions into one factor which was labeled supportive parenting (Duriez et al. 2007; Miklikowska et al. 2011).

A handful of studies have investigated associations between parenting and adolescents' conflict management and frequency. For instance, a few longitudinal studies revealed that a responsive parenting climate was prospectively related to an increased use of constructive problem solving skills, characterized by compromise and low avoidance, as well as a reduction in conflicts. A rejecting and controlling parenting climate, by contrast, was predictive of an increase in conflicts and maladaptive problem solving skills, characterized by hostile behaviors (Capaldi et al. 1994; Rubenstein and Feldman 1993; Rueter and Conger 1995a; 1995b). Further, recent multi-informant cross-sectional work (Missotten et al. 2016) has indicated that maternal responsiveness was positively associated with positive problem solving (see also Tucker et al. 2003), and negatively with withdrawal. Maternal psychological control was associated with more conflict engagement, withdrawal, and compliance. Bender and colleagues (2007) found that adolescents who experienced harsh parenting appeared to express less warmth and empathy during conflict interactions with their mother, and withdrew more often from the conflict. In general, supportive parenting might create a secure context that allows adolescents and mothers to handle their conflicts constructively (van der Giessen et al. 2014), whereas negative controlling parenting threatens adolescents' increasing need for autonomy (Soenens and Vansteenkiste 2010). This need frustration might evoke reactant behaviors (Van Petegem et al. 2015), which would interfere with constructive conflict management. Therefore, the present study not only examined the longitudinal associations between parenting and adolescents' conflict management, but also tested whether adolescents' reactance could explain why perceived parenting is predictive of adolescents' conflict management styles. These research questions are addressed in a longitudinal design to fully capture the temporal processes.

\section{Reactance}

The construct reactance stems from Brehm's (1966) psychological reactance theory and refers to a negative motivational state that drives individuals to regain their threatened or lost freedom (Brehm and Brehm 1981). In other words, reactance refers to one's direct rejection of authority and a tendency to do the opposite of what is expected. Although reactance initially was depicted as a state phenomenon, it was later added that there are also individual differences in reactance proneness, meaning that some persons are more sensitive to authority and restrictions of freedom in general and, consequently, they will behave more reactant than others (Brehm and Brehm 1981; Dillard and Shen 2005; Quick and Stephenson 2007). Although relatively understudied in adolescent psychology, reactance is highly relevant in the context of parent-adolescent relationships because it is assumed to become more prominent during adolescence (Miller and Quick 2010).

In the present study, we aimed to test whether individual differences in reactance were related to the use of certain conflict styles toward mothers. Although no studies to date have investigated these specific associations, previous studies provided cross-sectional evidence that reactance relates to more internalizing and externalizing problems, and school problems (Van Petegem et al. 2015; Vansteenkiste et al. 2014). Also, research on the personality profile of reactant individuals has demonstrated that these individuals were more dominant, less compliant, exhibited less self- 
control, and showed less interest in taking care for others (Dowd 1999). From these findings, one could expect that reactance especially would be predictive of rather dysfunctional conflict management strategies.

Moreover, reactance might be a possible candidate to explain why certain parenting dimensions relate to certain conflict management styles and frequency. Recent research suggests that controlling parenting would be predictive of adolescents' reactance proneness. Indeed, controlling parenting (i.e., intrusive and coercive parenting) was positively associated with adolescents' reactance, whereas autonomysupportive parenting was negatively associated with reactance, both cross-sectionally and prospectively (Van Petegem et al. 2015; Vansteenkiste et al. 2014). Although no studies to date directly investigated these associations, reactance previously has been found to explain the relation between parenting and other adolescent outcomes such as behavioral problems and study attitudes (Van Petegem et al. 2015). In other words, our mediation hypothesis implies that negative controlling parenting would evoke reactance in adolescents, which, in turn, would relate to the use of certain less adaptive conflict management styles and more conflicts. Supportive parenting, on the other hand, might protect against maladaptive conflict styles through decreasing reactant tendencies toward parents.

\section{The Present Study}

To test our hypotheses regarding direct and mediation effects, a longitudinal design with three waves is warranted because mediation aims to capture a process, wherein temporal separation between the independent variable, mediator, and dependent variable is required (Cole and Maxwell 2003; Little et al. 2007). Guided by three research questions, the current study adds to the literature in several ways. First, this study is the first to investigate the longitudinal effects of perceived maternal parenting on adolescents' conflict management styles and frequency (Research Question 1). Based on the literature, we expected supportive parenting to relate positively to positive problem solving, and negatively to conflict frequency, conflict engagement, and withdrawal over time.

Second, we examined over-time associations of reactance with adolescents' conflict management styles and frequency (Research Question 2). Based on the literature, we expected that adolescents' reactance would install a more conflictual family climate. With regard to conflict management styles, we expected reactance to be positively associated with conflict engagement (i.e., fighting and yelling), and negatively with compliance and problem solving. Third, we also tested whether reactance would explain the links between parenting and conflict management styles and frequency (Research Question 3). More specifically, unsupportive controlling parenting was hypothesized to relate to more conflicts and conflict engagement via reactance. As most previous studies on the associations between parenting and conflict management were cross-sectional in nature, this study can substantially advance the field by incorporating a longitudinal perspective.

All our hypotheses are based on the assumption that parenting is an important context for adolescent development (Steinberg 2001). However, there is considerable evidence that children actively shape their parenting environment as well, and that parents and children mutually influence each other (Belsky 1984; Klahr and Burt 2014). Previous longitudinal work has demonstrated that parents react to adolescent problem behaviors by withdrawal and lower displays of support (Kerr and Stattin 2003). Other scholars have argued that adolescents' problem behavior might elicit even more parental control efforts in order to regulate the child's behavior (Chen et al. 2000). Hence, in the context of the present study, adolescents' reactance or conflict management might have a direct impact (positive or negative) on maternal parenting as well. Therefore, we also explored possible child effects from adolescents' reactance, conflict management, and frequency to parenting.

\section{Method}

\section{Participants and Procedure}

Participants were drawn from the first three annual timepoints of the Leuven CoMPASS study (Conflict with Mothers and Personality in Adolescence: Study of resolution Styles), an ongoing longitudinal study of Dutchspeaking high school students from three schools in Flanders, Belgium. The first time-point was collected in 2013 and consisted of 819 adolescents from Grades 7-9. At Time 2,724 adolescents participated, and at Time 3731 adolescents participated. The mean participant age at Time 1 was 12.99 years $(\mathrm{SD}=1.00$; range $11-15,52 \%$ girls). A total of $86.4 \%$ of adolescents lived in intact families. Adolescents were included in the present study if they participated on T1. In this final sample, $19 \%$ of the data at the scale-level was missing because of participant drop-out. Little's missing completely at random test (Little 1988) revealed a normed $\chi^{2}\left(\chi^{2} / \mathrm{df}\right)$ of 1.56 , indicating that missing data could be reliably dealt with (Bollen 1983). Subsequently, we used the full information maximum likelihood (FIML) procedure provided in Mplus 7.3 (Muthén and Muthén 1998). This procedure uses all available information (including information from participants with missing data) to estimate the model parameters (Enders 2010). 
Prior to the study, all parents received an information letter, wherein they could refuse their child's participation. This resulted in exclusion of about $20 \%$ of the potential sample. On the day of the data collection, all adolescents received an informed consent letter wherein anonymity and confidentiality were guaranteed. About $5 \%$ of the adolescents did not give their assent to participate and were excluded from the study. All participants filled out the questionnaire electronically in a classroom under supervision of a research assistant. This procedure was approved by our university's institutional review board.

\section{Measures}

\section{Conflict management styles}

Adolescents completed the conflict resolution style inventory (CRSI; Kurdek 1994). This questionnaire was originally designed to measure conflict management in couples, but was adapted for the parent-child context (Branje et al. 2009). The validity of this adapted measure has been demonstrated in various studies (e.g., Missotten et al. 2011; Van Doorn et al. 2008). This questionnaire measures four conflict management styles (5 items each): Positive problem solving, conflict engagement, withdrawal, and compliance. On a 5-point Likert scale, ranging from 1 (never) to 5 (always), adolescents rated how often they themselves used particular conflict management strategies when they had a quarrel with their mother. Sample items included: "Trying to find solutions that are acceptable for both of us" (positive problem solving), "Letting myself go, and saying things I don't really mean" (conflict engagement), "Not listening to her anymore" (withdrawal), and "Not defending my opinion" (compliance). Cronbach's alphas on T1, T2, and T3 were, respectively: Positive problem solving $(\alpha=.82, .85$, and .86), conflict engagement ( $\alpha=.81, .84$, and .85), withdrawal $(\alpha=.75, .78$, and .83), and compliance $(\alpha=.68, .72$, and .79)

\section{Conflict frequency}

The frequency of conflicts between adolescents and mothers was measured with an adapted version of the interpersonal conflict questionnaire (ICQ; Laursen 1993). This questionnaire consists of 12 items covering potential conflict topics that were rated on a 5-point scale ranging from 1 (never) to 5 (often). Adolescents rated for each item how often they had conflicts, disagreements, or quarrels about a specific topic during the last week. All conflict topics refer to the adolescent's behavior and not the mother's behavior. Items included issues like: "sleeping during the weekends" and "spending time with friends". Scores were averaged across the 12 items, providing us with an average weekly conflict score. Cronbach's alphas were $.90, .88$, and .89 on $T 1, T 2$, and $T 3$, respectively.

\section{Parenting dimensions}

Adolescents' perceptions of maternal responsiveness was assessed with a 7-item scale of the child report on parent behavior inventory (CRPBI; Schaefer 1965b; Schludermann and Schludermann 1988). A sample item is "My mother often smiles to me". Perceived autonomy support was measured with the 7-item autonomy support scale of the perceptions of parents scale (POPS;Grolnick et al. 1991). A sample item reads "My mother allows me to make my own decisions". Perceived psychological control was assessed with the 8-item psychological control scale-youth selfreport (PCS-YSR;Barber 1996). A sample item reads "My mother is less friendly to me if I don't see things as she does". Perceived harsh control was assessed with 6 items from the verbal hostility and physical coercion scales of the parenting practices questionnaire (PPQ; Robinson et al. 1995). A sample question is "My mother hits me when I am not compliant". All items were rated on 5-point Likert scales ranging from 1 (does not apply at all) to 5 (applies strongly). The Dutch translations of these scales have been validated in several empirical studies (e.g., Soenens et al. 2006). Cronbach's alphas on T1, T2, and T3 were: Responsiveness $(\alpha=.89, .90$, and .91$)$, autonomy support ( $\alpha=.72, .77$, and .83), psychological control $(\alpha=.76, .79$, and .82), and harsh control $(\alpha=.83, .83$, and .82).

\section{Reactance}

Adolescents' reactance proneness toward mothers was assessed using a recently developed scale (Vansteenkiste et al. 2014), which was implemented in recent studies (Van Petegem et al. 2013; Van Petegem et al. 2015). The measure assesses compulsive noncompliance and a blunt rejection of the parental authority (e.g., "I do exactly the opposite of what my mother expects me to do"). The final scale consisted of 8 items and had a good reliability on $T 1, T 2$, and $T 3(\mathrm{a}=.85, .87$, and .85).

\section{Plan of Analyses}

We tested our hypotheses through path analyses. Although a fully latent cross-lagged model would be preferable in order to take into account measurement error, the large amount of parameters in such a latent model created convergence problems. Therefore, we constructed a hybrid cross-lagged panel model with a combination of manifest and latent variables. Specifically, parenting was modeled as a latent variable with the four parenting scales as indicators, whereas the other variables were modeled as manifest 
Table 1 Correlations among the study variables at Time 1

\begin{tabular}{|c|c|c|c|c|c|c|c|c|c|c|}
\hline Variable & $\mathrm{M}(\mathrm{SD})$ & 1 & 2 & 3 & 4 & 5 & 6 & 7 & 8 & 9 \\
\hline $\begin{array}{l}\text { 1. Autonomy } \\
\text { support }\end{array}$ & $3.61(.59)$ & & & & & & & & & \\
\hline 2. Responsiveness & $4.02(.75)$ & $.65 * * *$ & & & & & & & & \\
\hline $\begin{array}{l}\text { 3. Psychological } \\
\text { control }\end{array}$ & $2.02(.61)$ & $-.56 * * *$ & $-.51 * * *$ & & & & & & & \\
\hline 4. Harsh control & $1.72(.64)$ & $-.53 * * *$ & $-.50 * * *$ & $.62 * * *$ & & & & & & \\
\hline 5. Reactance & $2.07(.62)$ & $-.45 * * *$ & $-.43 * * *$ & $.54 * * *$ & $.50 * * *$ & & & & & \\
\hline $\begin{array}{l}\text { 6. Conflict } \\
\text { frequency }\end{array}$ & $2.17(.78)$ & $-.35 * * *$ & $-.32 * * *$ & $.39 * * *$ & $.40 * * *$ & $.43 * * *$ & & & & \\
\hline 7. Problem solving & $2.90(.82)$ & $.44 * * *$ & $.47 * * *$ & $-.31 * * *$ & $-.30 * * *$ & $-.38 * * *$ & $-.16^{* * *}$ & & & \\
\hline $\begin{array}{l}\text { 8. Conflict } \\
\text { engagement }\end{array}$ & $1.88(.76)$ & $-.34 * * *$ & $-.23 * * *$ & $.43 * * *$ & $.49 * * *$ & $.49 * * *$ & $.34 * * *$ & $-.24 * * *$ & & \\
\hline 9. Withdrawal & $2.36(.73)$ & $-.34 * * *$ & $-.31 * * *$ & $.44 * * *$ & $.35 * * *$ & $.40 * * *$ & $.27 * * *$ & $-.32 * * *$ & $.38 *$ & \\
\hline 10. Compliance & $2.15(.62)$ & -.01 & $.08 *$ & $.09 *$ & .01 & $-.11 * *$ & .03 & $.15 * * *$ & -.05 & $.24 * * *$ \\
\hline
\end{tabular}

variables. In this model, we estimated the direct paths from the latent parenting variable and reactance to the five conflict variables (i.e., conflict frequency and the four conflict management styles), and from parenting to reactance. Control paths from age and gender to all study variables were included. We also controlled for all lagged effects among the five conflict variables. Finally, all within-time associations at Times 1-3 and all autoregressive paths (from $T 1$ to $T 2$, from $T 2$ to $T 3$, and from $T 1$ to $T 3$ ) were estimated. To evaluate model fit, we used the chi-squared index, which should be as small as possible; the root mean square error of approximation (RMSEA), which should be less than .10, and preferably .06 , for adequate fit; the standardized root mean square residual (SRMR), which should be less than .10; and the comparative fit index (CFI), which should exceed .90, and preferably .95 (Hu and Bentler 1999; Kline 2005).

Path analyses then proceeded in the following steps. In the first model, with respect to the measurement of the latent parenting variable, the factor loadings of parenting were freely estimated. In the second model, to assess measurement invariance for this latent factor over time, the factor loadings were constrained to be equal across both time intervals. The null hypothesis of invariant factor loadings across subsequent waves would be rejected if it least two of the following criteria were satisfied (Cheung and Rensvold 2002; Vandenberg and Lance 2000): $\Delta \chi^{2}$ significant at $p<.05 ; \Delta \mathrm{CFI} \geq .01$; and $\triangle \mathrm{RMSEA} \geq .015$. In the third step, after establishing this measurement invariance for the parenting factor, the cross-lagged paths were constrained to be equal over time. Invariance test were again used to evaluate whether the constrained model could be retained. In the final model, we tested our mediation hypothesis according to the recommendations of Cole and Maxwell (2003). That is, we tested whether the indirect effects from the parenting dimension via reactance to the conflict variables were significant with the indirect command in Mplus. We also evaluated based on the modification indices whether additional paths (possible child effects from reactance and the conflict variables to the parenting dimensions) needed to be included as well to improve model fit (Cole and Maxwell 2003). Finally, to obtain confidence intervals for the indirect effects, the final models were run using the bootstrap option (set at 1,000 runs).

\section{Results}

\section{Path Analyses}

Means, standard deviations, and correlations among all study variables at $T 1$ are depicted in Table 1. Descriptive statistics and correlations among the study variables at the three timepoints are presented in Table 2 . The model with the constrained factor loadings had a good fit $\left(\chi^{2}\right.$ $(289)=962.356, p<.001 ; \quad \mathrm{RMSEA}=.05 ; \quad \mathrm{SRMR}=.05$; $\mathrm{CFI}=.94)$, and invariance tests over time indicated that this constrained model fitted the data equally well as the baseline model without such constraints $\left(\Delta \chi^{2} \quad(6)=25.25\right.$, $p<.001$; but $\Delta \mathrm{CFI}<01 ; \triangle \mathrm{RMSEA}<.01)$. Responsiveness and autonomy support loaded positively on the parenting factor (standardized loadings of .74 and .79, p's $<.001$, respectively), whereas psychological and harsh control had negative factor loadings $(-.76$ and $-.72, p$ 's $<.001$, respectively). Therefore, this parenting factor was labeled supportive parenting. The model with the constrained cross- 


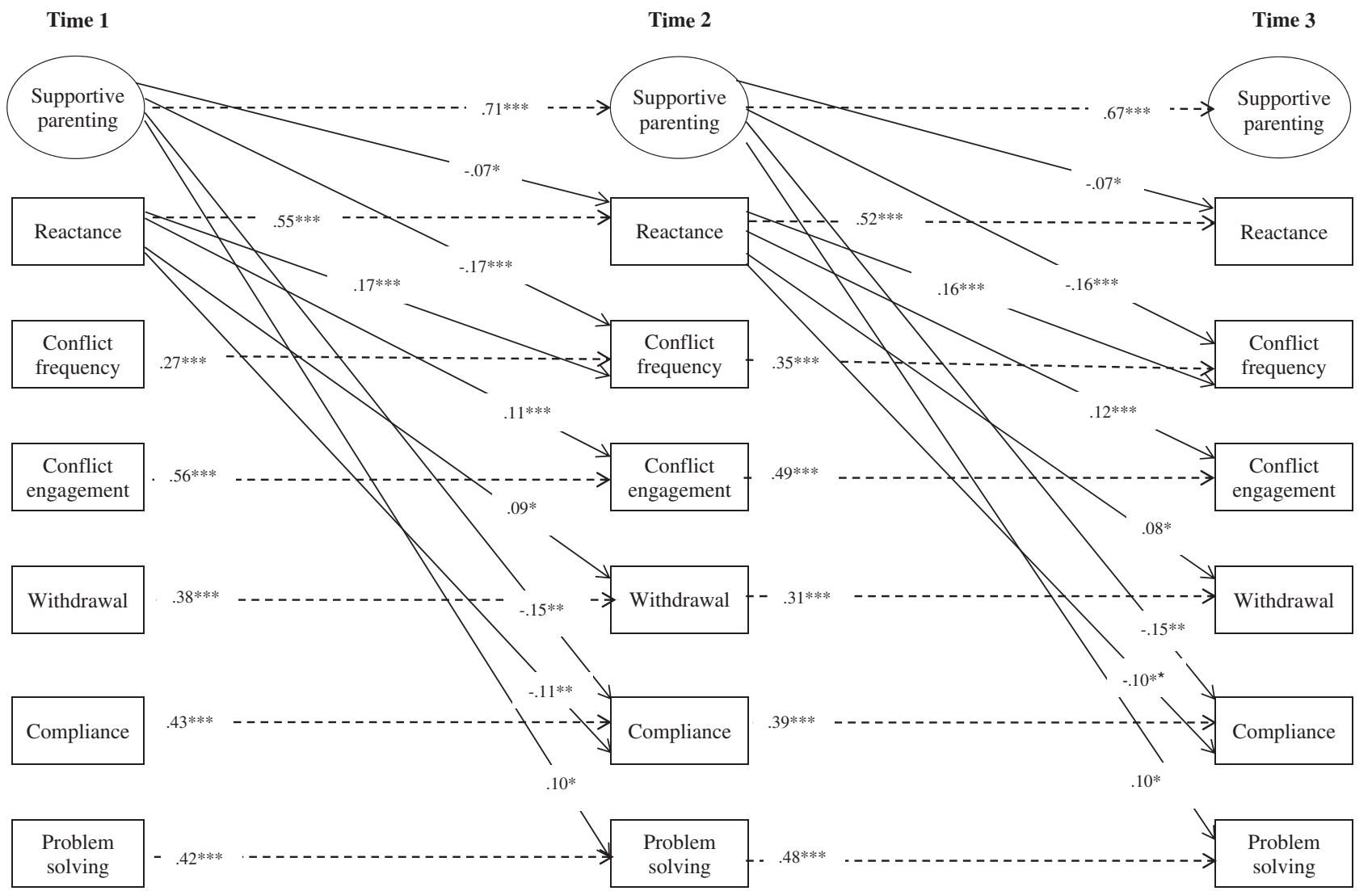

Fig. 1 Longitudinal path model of supportive parenting, reactance and conflict management styles and frequency. Standardized coefficients of significant effects are presented. $* p<.05$. $* * p<.01$. *** $p<.001$

lagged paths also had a good fit $\left(\chi^{2}(320)=1009.246, p\right.$ $<.001 ; \quad \mathrm{RMSEA}=.05 ; \quad \mathrm{SRMR}=.05 ; \quad \mathrm{CFI}=.94)$, and invariance test revealed that this more parsimonious invariant model did not result in a significant loss in model fit $\left(\Delta \chi^{2}\right.$ $(31)=46.89, p=.034$; but $\Delta \mathrm{CFI}=<01 ; \Delta \mathrm{RMSEA}<.01)$. Hence, we retained the model with longitudinal constraints on both the factor loadings and cross-lagged paths.

The final model is depicted in Fig. 1. For reasons of clarity, we did not present the control paths from age and gender to the study variables in the figure, nor the crosslagged paths among the five conflict variables. Concerning the paths from age and gender, we found that younger adolescents reported more positive parenting and more compliance, and less reactance than older adolescents $(\beta=-.09, p=.024 ; \beta=-.08, p=.034 ; \beta=.11, p<.001$; respectively). Boys reported less positive parenting and more reactance than girls $(\beta=-.10, p=.016 ; \beta=.11$, $p<.001$; respectively). Regarding the over-time associations between the five conflict variables, problem solving predicted less withdrawal over time $(\beta=-.12, p<.001)$, and compliance predicted less conflict engagement ( $\beta=-.06, p=.013)$. Based on the modification indices, no additional cross-lagged paths pointing to child effects had to be included.
In this final model, supportive parenting was positively related to problem solving, and negatively to conflict frequency, compliance, and reactance over time. Reactance was positively associated with conflict frequency, conflict engagement, and withdrawal over time, and negatively with compliance. The indirect effects from supportive parenting via reactance to conflict frequency, conflict engagement, withdrawal, and compliance, however, were not significant (point estimate $=-.014, \quad \mathrm{SE}=.008, \quad p=.074, \quad$ biascorrected 95\% CI $[-.022, .001]$; point estimate $=-.010$, $\mathrm{SE}=.006, p=.095$, bias-corrected $95 \%$ CI $[-.017, .001]$; point estimate $=-.008, \mathrm{SE}=.005, p=.134$, bias-corrected $95 \%$ CI $[-.013, .002]$; point estimate $=.008, \mathrm{SE}=.005$, $p=.149, \quad$ bias-corrected $\quad 95 \% \quad$ CI $\quad[-.002, .016]$, respectively).

\section{Additional Analyses}

As a set of ancillary analyses, we ran a cross-lagged model with the four parenting dimensions as manifest variables to get a clearer understanding of which specific parenting dimensions related to reactance and conflict management styles and frequency. However, some suppression effects were observed (e.g., maternal warmth and autonomy 
support relating to increases in withdrawal over time), which are likely due to the high correlations among the four parenting dimensions. Hence, in a next step, we ran the cross-lagged models for the four parenting dimensions separately. Each of the four models had a good fit to the data and the paths could be constrained over time. The overtime associations between reactance and the conflict management styles and conflict frequency were identical to those in the hybrid cross-lagged model. Concerning the associations with parenting, only the negative parenting dimensions psychological and harsh control were positively related to reactance. This suggests that the negative association between the latent parenting variable and reactance may be mainly driven by controlling parenting and not so much by warm and autonomy-supportive parenting. Regarding the associations between parenting and the conflict variables, the separate analyses provided a more nuanced picture than the model with the latent parenting factor. Both supportive parenting dimensions were positively related to problem solving, and autonomy support also was negatively related to conflict frequency and compliance. The two controlling parenting dimensions were positively related to conflict frequency and withdrawal. Psychological control was also positively related to compliance, and harsh control to conflict engagement. Finally, reactance was a mediating variable in the longitudinal associations between harsh control and conflict frequency and engagement (as based on the Indirect command in Mplus), indicating that harsh parenting was related to more hostile conflict behaviors via reactance. The detailed results of these additional analyses can be obtained from the first author.

\section{Discussion}

How adolescents' handle conflicts in the parent-adolescent relationship impacts the quality of this relationship and adolescents' psychosocial functioning in general (Branje et al. 2009; Caughlin and Malis 2004a, b). However, it still remains unclear as to why certain adolescents handle conflicts in a constructive manner while others have more difficulties in handling conflicts adequately (Eisenberg et al. 2008). Therefore, we examined two potential determinants of adolescents' conflict management styles and frequency toward mothers using a large sample in a multi-wave prospective design. The present study aimed to give insight into the longitudinal associations between supportive parenting and adolescents' conflict management and frequency, and what the role of reactance in these associations may be. Both parenting and reactance were uniquely related to conflict management styles and frequency one year later. Our findings did not fully support the role of reactance as a mediating mechanism in the associations between parenting and conflict management styles and frequency.

With regard to the longitudinal associations between parenting and conflict management styles and conflict frequency, our hypotheses were confirmed. Supportive parenting was positively related to increases in adolescents' positive problem solving over time. These findings are in line with previous research showing that parental support correlates with relatedness, negotiation, and adequate problem solving during conflicts (Allen et al. 2003; Missotten et al. 2016; Rubenstein and Feldman 1993). Similarly, maternal autonomy support recently has been found to relate to more adequate emotion regulation strategies in adolescents (Brenning et al. 2015). Indeed, to reach a compromise, adolescents need to be able to optimally regulate the emotions they experience during a conflict. In sum, a warm parenting climate and the support of volitional functioning sets the stage for adolescents to deal with conflicts constructively.

Supportive parenting was also associated with fewer conflicts over time. Many conflicts in adolescence are about autonomy-related issues, so when parents are supportive of the child's autonomy and are willing to take their perspective, there is less of a need for adolescents to engage in conflicts, and when they do, they are more inclined to resolve these in a positive way (Van der Giessen et al. 2014; Van der Giessen et al. 2015). Alternatively, it might also be that adolescents who are raised in a supportive climate perceive disagreements with their parents differently. As these adolescents are stimulated to make their own choices, it could be that differences in opinion between adolescents and mothers are more normative, but are perceived as rather helpful in making self-endorsed decisions, rather than as conflict-provoking.

Further, supportive parenting was associated with less compliance over time. As supportive parenting involves being warm and empathic toward adolescents' perspectives, and giving adolescents the opportunity to make selfendorsed choices (Grolnick 2002), they are less likely to feel pressured to comply in such a climate. Overall, our findings are consistent with the view that warm and facilitating parenting fosters an open climate for adolescents to disclose about personal issues (Soenens et al. 2006) and to find constructive compromises when different opinions occur, rather than feeling pressured to comply submissively.

In our hybrid cross-lagged model, supportive parenting was not associated with the negative conflict management styles. However, additional analyses with the four parenting dimensions separately revealed that psychological control was mainly related to the passive conflict styles withdrawal and compliance. Indeed, adolescents who are raised in a manipulative and intrusive way typically react more passively to conflicts by avoiding them (Assor et al. 2004; 
Bender et al. 2007) or by merely giving in to their mother. This passive way of dealing with conflicts might be explained by the possible induction of anxiety and guilt through psychologically controlling tactics (Assor et al. 2004). Harsh control was predictive of more conflict engagement and withdrawal, and less positive problem solving. In other words, it seems that harsh control prompts active as well as more passive maladaptive conflict styles. From a social learning perspective, it makes sense that in a hostile parenting climate (e.g., shouting or hitting), adolescents will adopt similar hostile conflict behaviors, such as scolding (Bandura 1977; Patterson 1982).

With regard to the over-time associations between reactance and adolescents' conflict management styles and frequency, the findings were largely in line with our expectations. Reactance was positively associated with conflict frequency, conflict engagement, and withdrawal, and negatively with compliance in both the hybrid model and the separate models. In other words, reactant adolescents seem to engage in more conflicts, tend to use a more aggressive way of handling conflicts or they withdraw from the conflict. Complying with mother's viewpoint, on the other hand, does not seem to be a preferable strategy for these adolescents. These findings correspond with the literature on the personality profile of reactant individuals, which is characterized by being dominant and exhibiting little self-control (Dowd 1999). Also, state reactance is conceptualized as a combination of anger and negative cognitions (Dillard and Shen 2005; Quick and Stephenson 2007), which may explain why adolescents high in reactance typically engage in more hostile conflict behaviors. Somewhat more surprising is the finding that more reactant adolescents also have a tendency to use a more passive approach, such as withdrawal, during conflicts. However, withdrawal during conflict is operationalized as avoiding to talk about the issue at hand or acting like one does not care. This is actually a form of passive-aggressive behavior that might be used by less verbal or more insecure adolescents.

As for our mediation hypotheses, reactance did not mediate the associations between parenting and the conflict styles and conflict frequency in the hybrid model (as indicated by a non-significant indirect effect). However, supportive parenting was negatively associated with reactance over time, indicating that unsupportive (controlling) parenting predicted more reactance. The separate analyses also revealed that the two negatively controlling parenting dimensions had a positive over-time association with reactance. Although we did not find evidence for reactance as a mediating mechanism in the hybrid model, the separate model with harsh control revealed that harsh control was positively associated with reactance, which, in turn, predicted higher levels of conflict and more conflict engagement. Moreover, the indirect effect in this separate model was found to be significant. This means that adolescents' reactance is evoked by harsh parenting and this partly explains the association between this aggressive way of parenting and aggressive conflict behaviors. It is important to note that indirect effects were small and should be interpreted with caution. In addition, a disadvantage of the separate models is that the associations with the other parenting dimensions were not taken into account. Taking all these findings together, we can conclude that supportive parenting and reactance were unique predictors of adolescents' conflict management styles and frequency over time. However, although parenting was also significantly related to reactance, there was limited support for reactance as a mediating mechanism in the longitudinal associations between parenting and conflict styles. This raises the question which other variables might be able to explain the links between parenting and adolescents conflict styles. Adolescents' emotion regulation strategies have been identified as an intervening mechanism explaining how parenting relates to adolescents' adjustment. For instance, autonomy-supportive parenting was related to more adequate integration of sad emotions which in turn positively predicted adolescents' well-being (Brenning et al. 2015). Based on these findings, future studies should examine whether supportive parenting can be related to constructive conflict management through the enhancement of emotion regulation.

Although this study has a number of strengths, including a large sample and a longitudinal design, some limitations warrant discussion. First, this study relied on self-report measures from the adolescent's perspective, which may lead to response bias and shared method variance. Although scholars have argued that adolescents are best placed to evaluate their parenting situation (Barber 1996), future studies should include mothers' perspective as well. Also, the conflict variables were assessed referring to conflict in general. Diary and observational studies could provide a more realistic picture of conflict behaviors as they occur from day to day (Burk et al. 2009). Second, we focused on the mother-adolescent relationship only. Future research should test whether our findings can be generalized to other family relationships, such as the father-adolescent relationship. Third, some of the cross-lagged coefficients obtained in this study were relatively small, but these coefficients were obtained while simultaneously controlling for all within-time associations and autoregressive paths. Adachi and Willoughby (2015) also argued that effects in longitudinal studies are much smaller than those in crosssectional studies due the inclusion of stability effects and autoregressive paths. These effects might warrant more caution and replication, but cannot be automatically dismissed as trivial. Fourth, our sample consisted mainly of Caucasian middle-class families that were recruited through 
schools. Future studies should try to include families from minority groups, as the content and impact of parent-child interactions could vary depending on the social environment in which families are embedded (Mandara and Murray 2002). Finally, adolescents' more general personality might also impact the way they handle conflicts, and might even moderate the impact of parenting on conflict management styles (Missotten et al. 2016). For instance, adolescents with a more overcontrolling personality style might react to controlling parenting by more internalizing conflict behaviors, such as withdrawal or compliance, whereas adolescents with a more undercontrolling style might react in a more externalizing way ( $\mathrm{Yu}$ et al. 2014). Future studies should investigate possible moderators of these associations, to unravel under which conditions these associations appear.

\section{Conclusions}

Our study showed that the affective nature of the motheradolescent relationship can give insight in why some adolescents develop constructive conflict strategies, whereas others display more difficulties in handling conflicts adequately. It appears that adolescents who feel accepted and encouraged by their mother to pursue their own goals and values experience fewer conflicts, and develop more constructive conflict management styles over time. Unsupportive and controlling parenting also seems to induce rebellious behaviors in adolescents, which might give rise to more destructive conflict styles. Adolescents' reactance towards maternal authority also relates to more conflicts and negative conflict styles above and beyond parenting. These findings are important for practitioners who work with troubled families. A recent study showed that interventions aimed at improving parents' autonomy-supportive communication skills were successful in enhancing children's well- being (Joussemet et al. 2014). It is a hopeful message that warm and supportive parenting helps adolescents to become adequate problem solvers. Other parents find it difficult to find an appropriate autonomy-supportive approach to address their child's increasing need for autonomy and the struggles that come with it. They sometimes use manipulative or hostile tactics to stay in control. Interventions that focus on how to communicate with adolescents with respect for their growing independence will foster adequate conflict management skills and more satisfying parent-adolescent relationships.

Author Contributions L.M. conceived of the study, participated in its design and coordination, performed the statistical analyses, and drafted the manuscript; K.L. conceived of the study, provided assistance with the statistical analyses, and helped to draft the manuscript; S.B. and S.V.P. assisted with the interpretation of the data, critical reading and feedback on the manuscript. All authors read and approved the final manuscript.

Funding This study was not funded by any research grant.

\section{Compliance with Ethical Standards}

Conflict of Interest The authors declare that they have no conflict of interest.

Ethical Approval This study was approved by the ethical review board of the faculty of Psychology and Educational Sciences, KU Leuven, Belgium.

Informed Consent All parents and adolescents were informed about the content and procedure of the study in advance. Parents could refuse their child's participation in the study. On the day of the data collection, informed consent was obtained from all individual participants included in the study.

\section{Appendix}

Table 2 


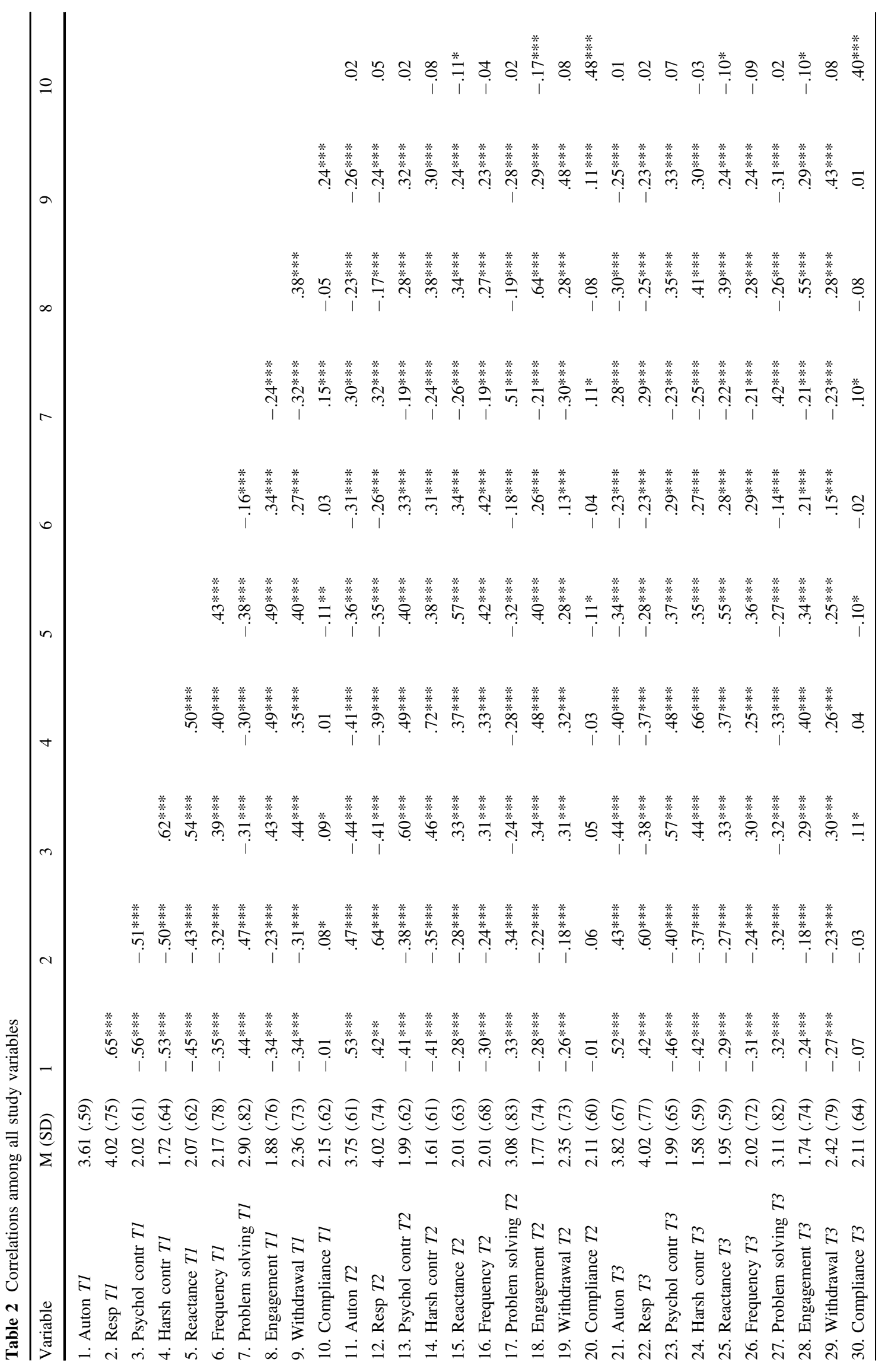




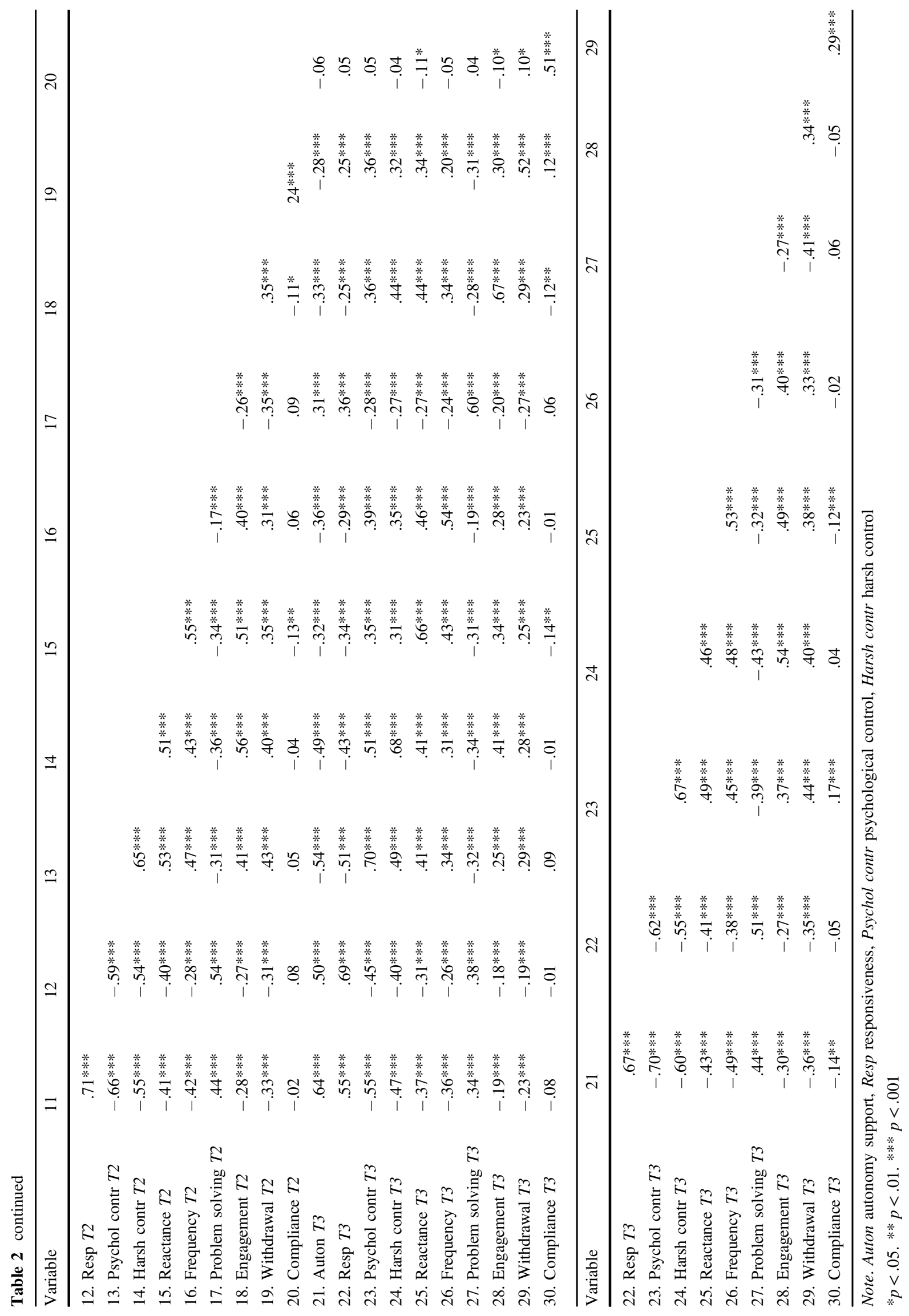




\section{References}

Adachi, P., \& Willoughby, T. (2015). Interpreting effect sizes when controlling for stability effects in longitudinal autoregressive models: Implications for psychological science. European Journal of Developmental Psychology, 12, 116-128.

Adams, R. E., \& Laursen, B. (2007). The correlates of conflict: disagreement is not necessarily detrimental. Journal of Family Psychology, 21, 445-458.

Allen, J., McElhaney, K., Land, D., Kuperminc, G., Moore, C., O'Beirne-Kelly, H., \& Kilmer, S. (2003). A secure base in adolescence: markers of attachment security in the mother-adolescent relationship. Child Development, 74, 292-307.

Assor, A., Roth, G., \& Deci, E. L. (2004). The emotional costs of parents' conditional regard: a self-determination theory analysis. Journal of Personality, 72, 47-88.

Bandura, A. (1977). Social learning theory. Englewood Cliffs, NJ: Prentice-Hall.

Barber, B. K. (1996). Parental psychological control: revisiting a neglected construct. Child Development, 67, 3296-3319.

Bender, H. L., Allen, J. P., McElhaney, K. B., Antonishak, J., Moore, C. M., Kelly, H. O. B., \& Davis, S. M. (2007). Use of harsh physical discipline and developmental outcomes in adolescence. Development and Psychopathology 19, (227-242.

Belsky, J. (1984). The determinants of parenting: a process model. Child Development, 55, 83-96.

Bollen, K. (1983). Structural equations with latent variables. New York, NY: Wiley. A.(1989).

Borawski, E. A., Ievers-Landis, C. E., Lovegreen, L. D., \& Trapl, E. S. (2003). Parental monitoring, negotiated unsupervised time, and parental trust: the role of perceived parenting practices in adolescent health risk behaviors. Journal of Adolescent Health, 33, 60-70.

Branje, S. J. T., van Doorn, M., van der Valk, I., \& Meeus, W. (2009). Parent-adolescent conflicts, conflict resolution types, and adolescent adjustment. Journal of Applied Developmental Psychology, 30, 195-204.

Brehm, J. W. (1966). A theory of psychological reactance. San Diego, CA: Academic.

Brehm, S. S., \& Brehm, J. W. (1981). Psychological reactance: A theory of freedom and control. San Diego, CA: Academic.

Brenning, K., Soenens, B., Van Petegem, S., \& Vansteenkiste, M. (2015). Perceived maternal autonomy support and early adolescent emotion regulation: a longitudinal study. Social Development, 24, 561-578.

Brody, G. H., Conger, R., Gibbons, F. X., Ge, X., McBride Murry, V., Gerrard, M., \& Simons, R. L. (2001). The influence of neighborhood disadvantage, collective socialization, and parenting on African American children's affiliation with deviant peers. Child Development, 72, 1231-1246.

Bronfenbrenner, U., \& Morris, P. A. (2006). The bioecological model of human development. In R. M. Lerner (Ed.). Handbook of child development: Vol. 1. Theoretical models of human development. 6th ed. (pp. 793-828). Hoboken, NJ: Wiley.

Burk, W. J., Denissen, J., van Doorn, M., Branje, S. J. T., \& Laursen, B. (2009). The vicissitudes of conflict measurement: stability and reliability in the frequency of disagreements. European Psychologist, 14, 153-159.

Capaldi, D. M., Forgatch, M. S., \& Crosby, L. (1994). Affective expression in family problem solving discussions with adolescent boys. Journal of Adolescent Research, 9, 28-49.

Caughlin, J. P., \& Malis, R. S. (2004a). Demand/withdraw communication between parents and adolescents: connections with selfesteem and substance use. Journal of Social and Personal Relationships, 21, 125-148.
Caughlin, J. P., \& Malis, R. S. (2004b). Demand/withdraw communication between parents and adolescents as a correlate of relational satisfaction. Communication Reports, 17, 59-71.

Chen, X., Liu, M., \& Li, D. (2000). Parental warmth, control, and indulgence and their relations to adjustment in Chinese children: a longitudinal study. Journal of Family Psychology, 14, 401-419.

Cheung, G. W., \& Rensvold, R. B. (2002). Evaluating goodness-of-fit indexes for testing measurement invariance. Structural Equation Modeling, 9, 233-255.

Cole, D. A., \& Maxwell, S. E. (2003). Testing mediational models with longitudinal data: questions and tips in the use of structural equation modeling. Journal of Abnormal Psychology, 112, 558-577.

Collins, W. A., Laursen, B., Mortensen, N., Luebker, C., \& Ferreira, M. (1997). Conflict processes and transitions in parent and peer relationships implications for autonomy and regulation. Journal of Adolescent Research, 12, 178-198.

Collins, W.A., \& Steinberg, L. (2006). Adolescent development in interpersonal context. In W. Damon \& R. Lerner (Series Eds.) \& N. Eisenberg (Vol. Ed.), Handbook of Child Psychology: Social, emotional, and personality development (Vol. 3, pp. 1003-1067). New York, NY: Wiley.

Darling, N., \& Steinberg, L. (1993). Parenting style as context: an integrative model. Psychological Bulletin, 113, 487-496.

Dillard, J. P., \& Shen, L. (2005). On the nature of reactance and its role in persuasive health communication. Communication Monographs, 72, 144-168.

Dowd, E. T. (1999). Toward a briefer therapy: overcoming resistance and reactance in the therapeutic process. In W. J. Mathews, \& J. H. Edgette (Eds.), Current thinking and research in brief therapy. New York, NY: Brunner/Mazel. Vol. III.

Duriez, B., Soenens, B., \& Vansteenkiste, M. (2007). In search of the antecedents of adolescent authoritarianism: the relative contribution of parental goal promotion and parenting style dimensions. European Journal of Personality, 21, 507-527.

Eisenberg, N., Hofer, C., Spinrad, T. L., Gershoff, E. T., Valiente, C., \& Losoya, S., et al. (2008). Understanding mother-adolescent conflict discussions: concurrent and across-time prediction from youths' dispositions and parenting. Monographs of the Society for Research in Child Development, 73(2), 1-180.

Enders, C. K. (2010). Applied missing data analysis. New York: Guilford Press.

Grolnick, W. S. (2002). The psychology of parental control: How well-meant parenting backfires. Mahwah, NJ: Lawrence Erlbaum Associates Publishers.

Grolnick, W. S., Ryan, R. M., \& Deci, E. L. (1991). Inner resources for school achievement: motivational mediators of children's perceptions of their parents. Journal of Educational Psychology, $83,508-517$.

Grotevant, H. D., \& Cooper, C. R. (1985). Patterns of interaction in family relationships and the development of identity exploration in adolescence. Child Development, 56, 415-428.

Hu, L. T., \& Bentler, P. M. (1999). Cutoff criteria for fit indexes in covariance structure analysis: conventional criteria versus new alternatives. Structural Equation Modeling: A Multidisciplinary Journal, 6, 1-55.

Janssens, A., Goossens, L., Van Den Noortgate, W., Colpin, H., Verschueren, K., \& Van Leeuwen, K. (2015). Parents' and adolescents' perspectives on parenting: Evaluating conceptual structure, measurement invariance, and criterion validity. Assessment, $22,473-489$.

Jones, T. S. (2001). Emotional communication in conflict. In F. Eadie, \& P. E. Nelson (Eds.), The language of conflict resolution (pp. 81-104). Thousand Oaks, CA: Sage.

Joussemet, M., Mageau, G. A., \& Koestner, R. (2014). Promoting optimal parenting and children's mental health: a preliminary 
evaluation of the How-to parenting program. Journal of Child and Family Studies, 23, 949-964.

Kerr, M., \& Stattin, H. (2003). Parenting of adolescents: action or reaction?. In A. C. Crouter \& A. Booth (Eds.), Children's influence on family dynamics: The neglected side of family relationships (pp. 121-151). Mahwah, NJ: Erlbaum.

Klahr, A. M., \& Burt, S. A. (2014). Elucidating the etiology of individual differences in parenting: a meta-analysis of behavioral genetic research. Psychological Bulletin, 140, 544-586.

Kline, R. B. (2005). Principles and Practice of Structural Equation Modeling (2nd ed.). New York, NY: The Guilford Press. ed.

Kuppens, S., Grietens, H., Onghena, P., \& Michiels, D. (2009). Measuring parenting dimensions in middle childhood: multitraitmultimethod analysis of child, mother, and father ratings. European Journal of Psychological Assessment 25, 133-140.

Kurdek, L. A. (1994). Conflict-resolution styles in gay, lesbian, heterosexual nonparent, and heterosexual parent couples. Journal of Marriage and the Family, 56, 705-722.

Laible, D. J., \& Carlo, G. (2004). The differential relations of maternal and paternal support and control to adolescent social competence, self-worth, and sympathy. Journal of Adolescent Research, 19, 759-782.

Laible, D. J., Carlo, G., \& Raffaelli, M. (2000). The differential relations of parent and peer attachment to adolescent adjustment. Journal of Youth and Adolescence, 29, 45-59.

Laursen, B. (1993). The perceived impact of conflict on adolescent relationships. Merrill-Palmer Quarterly, 39, 535-550.

Laursen, B., \& Collins, W. A. (2009). Parent-child relationships during adolescence. In R. M. Lerner, L. Steinberg (Eds.). Contextual influences on adolescent development (3rd ed.). Handbook of adolescent psychology, Vol. 2 (pp. 3-42). Hoboken, NJ: Wiley.

Little, R. J. (1988). A test of missing completely at random for multivariate data with missing values. Journal of the American Statistical Association, 83, 1198-1202.

Little, T. D., Preacher, K. J., Selig, J. P., \& Card, N. A. (2007). New developments in latent variable panel analyses of longitudinal data. International Journal of Behavioral Development, 31, $357-365$.

Mandara, J., \& Murray, C. B. (2002). Development of an empirical typology of African American family functioning. Journal of Family Psychology, 16, 318-337.

Miklikowska, M., Duriez, B., \& Soenens, B. (2011). Family roots of empathy-related characteristics: the role of perceived maternal and paternal need support in adolescence. Developmental Psychology, 47, 1342-1352.

Miller, C. H., \& Quick, B. L. (2010). Sensation seeking and psychological reactance as health risk predictors for an emerging adult population. Health Communication, 25, 266-275.

Missotten, L. C., Luyckx, K., Branje, S., Vanhalst, J., \& Goossens, L. (2011). Identity styles and conflict resolution styles: associations in mother-adolescent dyads. Journal of Youth and Adolescence, 40, 972-982.

Missotten, L. C., Luyckx, K., Van Leeuwen, K., Klimstra, T., \& Branje, S. (2016). Adolescents' conflict resolution styles toward mothers: the role of parenting and personality. Journal of Child and Family Studies, 25, 1-18.

Muthén, L. K., \& Muthén, B. O. (1998-2012). Mplus User's Guide. Seventh Edition Los Angeles, CA: Muthén \& Muthén.

Nelson, D. A., \& Crick, N. R. (2002). Parental psychological control: implications for childhood physical and relational aggression. In B. K. Barber (Ed.). Intrusive parenting: How psychological control affects children and adolescents (pp. 168-189). Washington, DC: APA.

Parke, R. D., \& Buriel, R. (2006). Socialization in the family: ethnic and ecological perspectives. In W. Damon (Series Ed.) \& N. Eisenberg (Vol. Ed.), Handbook of child psychology: Vol. 3.
Social, emotional, and personality development (5th ed., pp. 779-862). New York, NY: Wiley.

Patterson, G. R. (1982). A social learning approach : Vol. 3. Coercive family process. Eugene, OR: Castalia Publishing Company.

Pruitt, D. G., \& Carnevale, P. J. (1993). Negotiation in social conflict. Pacific Grove, CA: Brooks/Cole.

Quick, B. L., \& Stephenson, M. T. (2007). Further evidence that psychological reactance can be modeled as a combination of anger and negative cognitions. Communication Research, 34, 255-276.

Robinson, C. C., Mandleco, B., Olsen, S. F., \& Hart, C. H. (1995). Authoritative, authoritarian, and permissive parenting practices: development of a new measure. Psychological Reports, 77, 819-830.

Rubenstein, J., \& Feldman, S. (1993). Conflict-resolution behavior in adolescent boys: antecedents and adaptational correlates. Journal of Research on Adolescence, 3, 41-66.

Rueter, M. A., \& Conger, R. D. (1995a). Antecedents of parentadolescent disagreements. Journal of Marriage and the Family, $57,435-448$.

Rueter, M. A., \& Conger, R. D. (1995b). Interaction style, problemsolving behavior, and family problem solving effectiveness. Child Development, 66, 98-115.

Schaefer, E. S. (1965b). Children's reports of parental behavior: an inventory. Child Development, 36, 413-424.

Schludermann, E. H., \& Schludermann, S. M. (1988). Children's Report on Parent Behavior (CRPBI-108, CRPBI-30) for older children and adolescents (Tech. Rep.). Winnipeg, MB, Canada: University of Manitoba, Department of Psychology.

Soenens, B., \& Vansteenkiste, M. (2010). A theoretical upgrade of the concept of parental psychological control: proposing new insights on the basis of self-determination theory. Developmental Review, 30, 74-99.

Soenens, B., Vansteenkiste, M., Lens, W., Luyckx, K., Goossens, L., Beyers, W., \& Ryan, R. M. (2007). Conceptualizing parental autonomy support: adolescent perceptions of promotion of independence versus promotion of volitional functioning. Developmental Psychology, 43, 633-646.

Soenens, B., Vansteenkiste, M., Luyckx, K., \& Goossens, L. (2006). Parenting and adolescent problem behavior: an integrated model with adolescent self-disclosure and perceived parental knowledge as intervening variables. Developmental Psychology, 42, 305-318.

Steinberg, L. (2001). We know some things: parent-adolescent relationships in retrospect and prospect. Journal of Research on Adolescence, 11, 1-19.

Steinberg, L., \& Silk, J. (2002). Parenting adolescents. In M. Bornstein (Ed.). Handbook of parenting: Volume 1. Children and parenting (2nd ed., pp. 103-133). Mahwah, NJ: Erlbaum.

Tucker, C. J., McHale, S. M., \& Crouter, A. C. (2003). Conflict resolution: links with adolescents' family relationships and individual well-being. Journal of Family Issues, 24, 715-736.

Vandenberg, R. J., \& Lance, C. E. (2000). A review and synthesis of the measurement invariance literature: suggestions, practices, and recommendations for organizational research. Organizational Research Methods, 3, 4-70.

Van der Giessen, D., Branje, S., Keijsers, L., Van Lier, P. A., Koot, H. M., \& Meeus, W. (2014). Emotional variability during mother-adolescent conflict interactions: longitudinal links to adolescent disclosure and maternal control. Journal of Adolescence, 37, 23-31.

Van der Giessen, D., Hollenstein, T., Hale III, W. W., Koot, H. M., Meeus, W., \& Branje, S. (2015). Emotional variability in motheradolescent conflict interactions and internalizing problems of mothers and adolescents: dyadic and individual processes. Journal of Abnormal Child Psychology, 43, 339-353. 
Van Doorn, M. D., Branje, S. J. T., \& Meeus, W. H. J. (2008). Conflict resolution in parent-adolescent relationships and adolescent delinquency. Journal of Early Adolescence, 28, 503-527.

Van Doorn, M. D., Branje, S. J., \& Meeus, W. H. (2011). Developmental changes in conflict resolution styles in parent-adolescent relationships: a four-wave longitudinal study. Journal of Youth and Adolescence, 40, 97-107.

Van Petegem, S., Vansteenkiste, M., \& Beyers, W. (2013). The jingle-jangle fallacy in adolescent autonomy in the family: in search of an underlying structure. Journal of Youth and Adolescence, 42, 994-1014.

Van Petegem, S., Vansteenkiste, M., Soenens, B., Beyers, W., \& Aelterman, N. (2015). Examining the longitudinal association between oppositional defiance and autonomy in adolescence. Developmental Psychology, 51, 67-74.

Vansteenkiste, M., Soenens, B., Van Petegem, S., \& Duriez, B. (2014). Longitudinal associations between adolescent perceived degree and style of parental prohibition and internalization and defiance. Developmental Psychology, 50, 229-236.

Weymouth, B. B., Buehler, C., Zhou, N., \& Henson, R. A. (2016). A meta-analysis of parent-adolescent conflict: disagreement, hostility, and youth maladjustment. Journal of Family Theory \& Review, 8, 95-112.

Yu, R., Branje, S. J., Keijsers, L., \& Meeus, W. H. (2014). Personality types and development of adolescents' conflict with friends. European Journal of Personality, 28, 156-167.
Lies Christine Missotten is a doctoral student in the Center for School Psychology and Development in Context at KU Leuven, Belgium. Her research focuses on conflict management styles between adolescents and mothers and the associations with parenting and personality. She is also interested in the daily dynamics of conflict behaviors.

Koen Luyckx ( $\mathrm{PhD}, \mathrm{KU}$ Leuven) is an assistant research professor in the Center for School Psychology and Development in Context at KU Leuven, Belgium. His research interests are mainly focused on identity and family dynamics in community, psychiatric, and medical samples.

Susan Branje ( $\mathrm{PhD}$, Radboud University Nijmegen) is a professor at the Center for Child and Adolescent Studies at Utrecht University, The Netherlands. Her research interests are understanding the developmental changes in adolescents' relationships with parents, siblings, friends, and romantic partners and the associations with development of adolescent adjustment.

Stijn Van Petegem ( $\mathrm{PhD}$, Universiteit Gent, Belgium) is a postdoctoral researcher at the Center de recherche sur la famille et le développement at the University of Lausanne, Switzerland. His research interests are adolescent autonomy, parenting, and identity development. 